\title{
RE-ANALYSIS AND CORRECTION OF BEDLOAD RELATION OF MEYER-PETER AND MÜLLER USING THEIR OWN DATABASE
}

\author{
By Miguel Wong ${ }^{1}$ and Gary Parker ${ }^{2}$
}

\begin{abstract}
The pioneering predictor of fluvial bedload transport rate proposed by Meyer-Peter and Müller in 1948 is still extensively used in basic research and engineering applications. A review of the basis for its formulation reveals, however, that an unnecessary bed roughness correction was applied to cases of plane-bed morphodynamic equilibrium. Its inclusion followed a flow resistance parameterization in terms of the Nikuradse roughness height, which has been shown (well after the publication of their work) to be inappropriate for the characterization of mobile bed rough conditions in rivers. Removing the unnecessary correction and incorporating an improved correction of the boundary shear stress due to sidewall effects allow elucidation of the most parsimonious form of the bedload relation of Meyer-Peter and Müller that is dictated by their own data set. The new predictor is presented in terms of two alternative power law forms. These amended forms show that, in the case of lower-regime plane bed equilibrium transport of uniform bed sediment, the new estimates of volume bedload transport rates are less than or equal to half the values that would be obtained with the original relation of Meyer-Peter and Müller in the absence of the unnecessary bed roughness correction. The meticulous database and clear analysis of the original work of Meyer-Peter and Müller greatly aided the present authors in their re-analysis, which liberally uses the hindsight offered by 57 years of subsequent research.
\end{abstract}

CE Database subject headings: Bed load, Boundary shear, Flow resistance, Wall friction, Bedforms, Flumes

\footnotetext{
${ }^{1}$ Graduate student, St. Anthony Falls Laboratory, University of Minnesota, \#2 $3^{\text {rd }}$ Ave SE, Minneapolis, MN 55414, Phone: (612)-624-4675, Fax: (612)-624-4398, e-mail: wong0228@umn.edu

2 Professor, Ven Te Chow Hydrosystems Laboratory, University of Illinois, 205 N Mathews Ave, Urbana, IL 61801, Phone: (217)-244-5159, Fax: (217)-333-0687, e-mail: parkerg@uiuc.edu
} 


\section{Introduction}

A focus of current research on sediment transport in rivers, particularly in the case of gravel-bed streams, is on developing more accurate predictors of the bedload transport rate. Estimating this rate usually involves relating it to mean characteristics of the driving force of the flow and the corresponding reach-averaged resistance properties of the bed. More than a century has passed since the introduction of the first mechanistic relation of this type by $\mathrm{Du}$ Boys in 1879 (Ettema and Mutel 2004), but still no formulation can be claimed to be of universal applicability. There is a lively debate, for instance, concerning the effects of turbulence and bed heterogeneities at micro and macro scales on bedload transport rates, but no agreement has been reached (see e.g., Ashworth et al. 1996; Cao and Carling 2002; Wilcock 2004).

One of the formulae most widely used in laboratory and field investigations as well as in numerical simulations of bedload transport is the empirical relation proposed by Meyer-Peter and Müller (1948; abbreviated to "MPM" below). This relation was derived from experiments carried out during a period of sixteen years in the flume facilities of the Laboratory for Hydraulic Research and Soil Mechanics of the Swiss Federal Institute of Technology (ETH) at Zürich, Switzerland. It allows estimation of the bedload transport rate in an open-channel, as a function of the excess bed shear stress applied by the flowing water. MPM worked out their relation from a comprehensive experimental data set for equilibrium bedload transport under steady, uniform flow that included 135 runs from ETH and 116 more runs from the set due to Gilbert (1914; abbreviated as "GIL" below). The data pertain to both sediment of uniform size and size mixtures, various values of sediment specific gravity, and cases both with and without the presence of bedforms. The original data of MPM were included in an internal report of ETH, but were not published until Smart and Jäggi’s paper (1983) on bedload transport on steep slopes. Review of the experimental techniques and data analysis carried out by MPM reveals a meticulous attention to detail.

The bedload transport relation of MPM has been used extensively for almost six decades. With only very few exceptions, this usage has not been accompanied by detailed re-analysis of the formula itself, the data on which it is based, and its range of validity. Re-analysis to date has concentrated on extension of the formula to: (i) channels that are steeper than those of the experiments by MPM (Smart and Jäggi 1983; Smart 1984), and (ii) poorly-sorted sediment mixtures (Hunziker 1995; Hunziker and Jäggi 2002). The simplest and most common case to which the relation of MPM is typically applied, i.e. the transport of uniform sediment over a flat bed with a slope not exceeding 0.02 , however, does not appear to have been revisited in the sole context of the original data used by 
MPM. Hence the question arises: Does the relation of MPM in fact fit the data used in its derivation? Answering this is of significance not only because the MPM bedload transport predictor is commonly used for comparative purposes in basic research (see e.g., Abdel-Fattah et al. 2004; Barry et al. 2004; Bettess and Frangipane 2003; Bolla Pittaluga et al. 2003; Bravo-Espinosa et al. 2003; Defina 2003; Gaudio and Marion 2003; Knappen and Hulscher 2003; Martin 2003; Mikoš et al. 2003; Nielsen and Callaghan 2003; Ota and Nalluri 2003; Singh et al. 2004; Yang 2005), but also because it is frequently used in engineering applications (it is one of the relationships available in HEC-6, a computer software used for sediment transport calculations that is very popular in the USA).

This paper is devoted to a thorough review of the basis for the formulation of the MPM relation, with special attention to the procedures by which bedform and sidewall corrections were applied by MPM. Hindsight offered by the results of more current research on sediment transport and flow resistance in rivers reveals that a) the form drag correction used by MPM in analyzing their data for plane-bed conditions is unnecessary, and b) if this unnecessary correction is omitted, then the MPM bedload transport relation needs to be modified in order to accurately reproduce the experimental observations used to derive it. The analysis presented here culminates in an amended form of the MPM relation for the case of lower-regime plane-bed equilibrium transport conditions. It is worth clarifying here that the goal of this paper is not to propose a new or improved universal predictor of the bedload transport rate, but to correct the data analysis and results of MPM for the case of plane-bed bedload transport in light of research results that have become available since the publication of their work.

It is equally important to point out that the present work is not the first one to conclude that the relation of MPM overpredicts bedload transport under plane-bed conditions in the absence of a form drag correction. Credit must go to Hunziker, Jäggi, and Smart for first recognizing this (Hunziker 1995; Hunziker and Jäggi 2002; Smart and Jäggi 1983; Smart 1984). The database used in their analysis is, however, larger than that used by MPM alone. As a result, it is not readily apparent that the relation of MPM significantly overpredicts (in the absence of a form drag correction) when applied solely to the data (for plane-bed transport) originally used in its derivation. Nor is it apparent that the form drag correction is not necessary for the plane-bed data of MPM. In this paper: (a) the overprediction in the absence of a form drag correction is demonstrated in the narrow context of the plane-bed data used by MPM, (b) the fact that a form drag correction is unnecessary for the plane-bed data used by MPM is made evident, and (c) simpler modified forms of MPM which are faithful to the original data set are presented. 
Fourteen references which use the original form of the MPM bedload transport equation without the form drag correction of MPM are presented in the third paragraph of this Introduction. All of these references were published subsequently to the works of Hunziker, Jäggi and Smart aforementioned. It is the hope of the authors that the present work, combined with the contributions cited above, will finally lead to the recognition that a) the MPM bedload equation without the MPM form drag correction overpredicts plane-bed bedload transport by a factor of about 2, b) the form drag correction of MPM is unnecessary for plane-bed conditions, and c) a modified form of the MPM bedload relation (with no form drag correction) that predicts significantly lower transport rates than the original MPM bedload relation (when used with no form drag correction) should be used in the future for plane-bed conditions.

\section{Empirical bedload transport relation}

Three data sets were used by MPM for the derivation of their bedload transport relation; they are named here ETH-up, GIL-up, and ETH-nup. ETH-up ("up" is an abbreviation for "uniform sediment, plane bed") consists of the results for 52 runs, all pertaining to plane-bed transport of material of uniform size (32 runs with $D_{m}=28.65 \mathrm{~mm}$, and 20 runs with $D_{m}=5.21 \mathrm{~mm}$, where $D_{m}=$ arithmetic mean diameter of the sediment) and with a constant value of submerged specific gravity of the sediment, $R$, of $1.68\left(R=\rho_{s} / \rho-1\right.$, where $\rho_{s}=$ density of the sediment, and $\rho=$ density of water). GIL-up similarly includes the results of 116 runs, all corresponding to plane-bed transport of material of uniform size (27 runs with $D_{m}=7.01 \mathrm{~mm}, 69$ runs with $D_{m}=4.94 \mathrm{~mm}$, and 20 runs with $D_{m}=3.17 \mathrm{~mm}$ ), with a constant value of $R$ of 1.65. ETH-nup ("nup" is an abbreviation for "not necessarily both uniform material and plane bed") comprises the results of 83 runs, in many of which bedforms were present (channel aspect ratio, $B / H$, varied between 1.7 and 72.2 , where $B=$ channel width, and $H=$ water depth), the sediment consisted of size mixtures $\left(D_{m}\right.$ ranged between 0.38 and $5.21 \mathrm{~mm}$, and $D_{90} / D_{m}$ varied between 1.00 and 2.52, where $D_{90}=$ particle size for which $90 \%$ of the sediment is finer by weight), and the value of $R$ differed from 1.68 ( $R$ ranged between 0.25 and 3.22). The descriptor "not necessarily" is motivated by the observation that although Meyer-Peter and Müller (1948) indicated that bedforms were present in many of the runs in this set ETH-nup, they do not specify which of the runs had bedforms and which did not. Since the focus of the present work is on the transport of uniform material over a plane bed, most of the data analysis herein is performed using the sets ETH-up and GIL-up. 
The relation proposed by MPM estimates the rate of bedload transport in a river as a function of the shear force exerted by the flowing water over the sediment bed. This relation evolved over time. A first form of the relation was presented by Meyer-Peter et al. (1934); it was based solely on the sets ETH-up and GIL-up, for which bedforms were not observed and the sediment could be approximated as uniform in size. An empirical analysis of these data resulted in the following equation:

$$
\frac{\left(\rho q_{w}^{\prime}\right)^{2 / 3} S}{D_{m}}=17+0.40 \frac{\left[\rho(R+1) q_{b}\right]^{2 / 3}}{D_{m}}
$$

where $q_{w}^{\prime}=$ volume discharge of water per unit channel width after including a correction for sidewall effects (details about which follow in the next section), $S=$ slope of the energy grade line, and $q_{b}=$ volume bedload transport rate per unit channel width. Equation (1) is not dimensionally homogenous, and requires the use of SI units.

The data from ETH-up and GIL-up are presented in Figure 1. The line of best fit shown in this figure was determined from a standard regression analysis; it is marginally different from equation (1), which Meyer-Peter et al. (1934) determined by eye. The slope of the line of best fit is thus 0.37 instead of the value of 0.40 proposed by MPM.

This first relation (1) was later modified (Meyer-Peter and Müller 1948) to include different values of specific gravity, as well as to extend the applicability to sediment mixtures. The modified expression is dimensionally homogeneous, and reduces to a functional relation between the bedload transport rate and the shear force exerted by the water in terms of two well-known dimensionless numbers on sediment transport in rivers: the Einstein and the Shields numbers. It is presented here as equation (2), in the dimensionless form first suggested by Chien (1954) that is completely equivalent to the original dimensioned equation (26) of Meyer-Peter and Müller (1948):

$$
\begin{aligned}
q^{*} & =8\left[\frac{q_{w}^{\prime}}{q_{w}}\left(\frac{K_{b}}{K_{r}}\right)^{3 / 2} \tau^{*}-0.047\right]^{3 / 2} \\
q^{*} & =\frac{q_{b}}{\sqrt{\operatorname{Rg} D_{m}} D_{m}} \\
\tau^{*} & =\frac{\tau_{0}}{\rho \operatorname{Rg} D_{m}}=\frac{H S}{R D_{m}}
\end{aligned}
$$

In the above relations $q^{*}=$ dimensionless volume bedload transport rate per unit channel width (Einstein number), $g=$ acceleration due to gravity, $q_{w}=$ volume discharge of water per unit channel width (without any sidewall 
correction; recall that $q_{w}^{\prime}=$ volume discharge of water per unit channel width after correcting for sidewall effects), $K_{b}=$ Manning-Strickler coefficient of roughness for the bed region, $K_{r}=$ Manning-Strickler coefficient of bed roughness associated with skin friction only (i.e. after form drag due to bedforms has been excluded), $\tau^{*}=$ dimensionless boundary shear stress (Shields number), and $\tau_{0}=$ boundary shear stress applied by the water over the sediment bed under normal flow conditions for a wide open-channel (without any sidewall correction). Separate experiments by MPM showed that the critical Shields number for the onset of sediment motion was about 0.030 (Meyer-Peter and Müller 1948), but an "effective" critical value of 0.047 was adopted instead in the formulation of equation (2) because it allowed a better fit of the data. The ratio of $q_{w}^{\prime}$ to $q_{w}$ (where $q_{w}^{\prime} \leq q_{w}$ ) represents the sidewall correction of MPM, while the ratio of $K_{b}$ to $K_{r}$ (where $K_{b} \leq K_{r}$ ) to the power of $3 / 2$ represents the bedform correction of MPM. Details about the sidewall and bedform corrections of MPM follow in the next sections. These two correction factors are rarely included in recent publications referring the MPM bedload transport relation, for reasons that are not necessarily clear.

All the results from the runs at ETH, i.e. ETH-up and ETH-nup, are presented in Figure 2 in a plot of Einstein number, $q^{*}$ versus Shields number, $\tau^{*}$. In this figure the data have been reduced using the aforementioned bedform and sidewall corrections. One issue to highlight here is that MPM applied a bedform correction even in cases for which bedforms were absent. The justification for doing that appears questionable (for more details, see discussion on page 57 and Fig. 12 of Meyer-Peter and Müller, 1948). MPM indicated that for a bedload transport rate substantially greater than the threshold value for particle incipient motion, part of the shear stress applied by the flowing water over the bed is absorbed by the particles in bedload transport. As a result, the effective force causing the movement of sediment is reduced, and a "bedform correction" needs to be included even if no bedforms are observed. However, the meaning of this ratio $K_{b} / K_{r}$ is interpreted in a different way in some classical books on sediment transport (Bogárdi 1974; Chang 1992; Garde and Ranga Raju 1985; Graf 1971; Raudkivi 1976; Simons and Şentürk 1977; Yang 1971). Four of these authors explicitly propose using a ratio $K_{b} / K_{r}=0.5$ when strong bedforms are present, and a ratio $K_{b} / K_{r}=1.0$ when bedforms are absent. Their interpretation of $K_{b} / K_{r}$ is therefore strictly related to the effects of bedforms and not at all on the effects of particles moving in bedload transport on the effective shear stress. It will be demonstrated in this paper that such a bedform correction, or in a more general context a correction accounting for bed resistance in addition to that due to skin friction, is actually not required for the data pertaining to lower-regime plane-bed equilibrium transport of uniform sediment used by MPM. 


\section{Flow resistance - Sidewall correction}

To determine the actual shear force exerted by the flowing water on the sediment bed, a separation of the effects due to the difference in roughness of the channel bed and sidewalls is needed. The sidewall correction of MPM cited above is based on the assumptions of uniform flow velocity throughout the cross section of the flow, equal energy slope on the bed and wall regions of the flow, and partitioning of the overall Manning-Strickler coefficient of roughness for a composite cross section, $K$, into a bed and a wall component, $K_{b}$ and $K_{w}$, respectively. In other words, partitioning is carried out in terms of hydraulic radii. It is worth mentioning at this stage that the different Manning-Strickler coefficients of roughness used here, all denoted by the capital letter $K$, are equal to the inverse of the corresponding Manning's $n$ in SI units, and are thus not at all the same parameters as the (Nikuradse or Kamphuis) bed roughness height, for which the notation $k_{s}$ is used here. In addition, it should be recalled from the empirical relation proposed by Manning-Strickler for normal flow (Manning 1891; Strickler 1923), that a larger value of $K$ should be interpreted as a smaller boundary resistance to the flow; hence, for a channel configuration like the one used by MPM in their flume experiments, $K_{b}<K$ for the gravel bed (rough boundary) while $K_{w}>K$ for the glass walls (smooth boundaries).

From the water continuity equation and the Manning-Strickler relation (used to estimate $K$ from the measured values of $q_{w}, B, H$, and $S$ ), applied in the case of a rectangular cross-section with wetted perimeters $B$ and $2 H$ for the bed and wall regions, respectively, the coefficient of roughness for the bed region, $K_{b}$, may be computed as:

$$
K_{b}=\frac{K K_{w} B^{2 / 3}}{\left[B K_{w}^{3 / 2}+2 H\left(K_{w}^{3 / 2}-K^{3 / 2}\right)\right]^{2 / 3}}
$$

Accordingly, the value of the sidewall-corrected water discharge per unit channel width, $q^{\prime}{ }_{w}$, can be obtained from:

$$
q_{w}^{\prime}=q_{w} \frac{B K_{w}^{3 / 2}}{2 H K_{b}^{3 / 2}+B K_{w}^{3 / 2}}
$$

The computed value of $q_{w}^{\prime}$ and the measured value of $q_{w}$ are then used in equation (2) to account for sidewall effects, such that the input value for the boundary shear stress represents the one effectively acting on the bed region alone. A major concern with this sidewall-correction methodology however, is that the coefficient of roughness for the wall region, $K_{w}$, is set in advance of the actual experiments on bedload transport. Its value is thus independent of $q_{w}$ and $B / H$ (see Figure 3), a result that does not seem to have a solid physical background. In this regard Hey (1979) and Yen (2002), among other researchers, state that the Darcy-Weisbach equation (Rouse 1946) for flow resistance has a 
stronger theoretical foundation, and its original formulation for pipe flow can be applied to open-channel flow in the following form:

$$
f=\frac{8 g r S}{u^{2}}
$$

where $f=$ overall Darcy-Weisbach roughness coefficient for a composite cross section, $r=$ hydraulic radius, and $u=$ mean flow velocity. In such a formulation the value of $f$ depends on the Reynolds number, $R e$, which in the case of open-channel flow is computed by using a characteristic length of $4 r(R e=4 u r / v$, where $v=$ kinematic viscosity of water).

The sidewall correction proposed by Vanoni and Brooks (Vanoni 1975) makes use of the Darcy-Weisbach formulation to estimate flow resistance, and is thus adopted here. The procedure again consists of partitioning the cross-section of the flow into two non-interacting parts, i.e. the bed and wall regions. As before, equal mean flow velocity and energy gradient in the bed and wall regions are assumed, so partitioning is in terms of hydraulic radii. All this translates into the relation given in equation (8) for iteratively calculating the roughness coefficient for the wall region, $f_{w}$, in the case of a smooth hydraulic boundary (Chien and Wan 1999):

$$
\frac{R e}{f}=\frac{10^{\left(\frac{1}{2 \sqrt{f_{w}}}+0.40\right)}}{f_{w}^{1.5}}
$$

From the water continuity equation and the Darcy-Weisbach relation applied to the case of a rectangular crosssection with wetted perimeters $B$ and $2 H$ for the bed and wall regions, respectively, the roughness coefficient for the bed region, $f_{b}$, may be computed as:

$$
f_{b}=f+\frac{2 H}{B}\left(f-f_{w}\right)
$$

By combining (7) and (9), one can estimate the value of the hydraulic radius on the bed region, $r_{b}$, and thus compute the corresponding shear velocity, $u_{b}^{*}$

$$
u_{b}^{*}=\sqrt{g r_{b} S}
$$

as well as the sidewall-corrected shear stress, $\tau_{b}$ :

$$
\tau_{b}=\rho\left(u_{b}^{*}\right)^{2}
$$


The bed shear stress computed following this procedure replaces the value of $\left(q_{w}^{\prime} / q_{w}\right) \tau_{0}$ that represented the original sidewall correction of MPM in equation (2). This results in the following improvements: not only is the expected dependence of flow resistance on $q_{w}$ and $B / H$ taken into account (see Figure 4), but also the dependence on the Reynolds number, $R e$.

\section{Flow resistance - Bedform correction}

The other correction factor included in equation (2) allows removal of the form drag component of the channel bed resistance, i.e. the component due to bedforms, so quantifying that component of the shear force of the water that actually causes bedload transport. In a more general framework, this bedform correction can be interpreted as that accounting for all other factors besides skin friction acting on immobile grains (e.g., grain shape, bed structure, moving bedload particles, bedforms, channel-scale morphology, surface waves, etc.) that contribute to flow resistance.

As opposed to the procedure for extracting sidewall effects, the bedform correction proposed by MPM consists of a partitioning of the slope of the energy grade line, $S$, into one related to form resistance and another associated with skin friction only, the latter being denoted as $S_{r}$. The implicit assumption is that the hydraulic radius used in the Manning-Strickler relation has the same value for both form resistance and skin friction. As a result, the bedform correction could be represented as:

$$
\frac{S}{S_{r}}=\left(\frac{K_{b}}{K_{r}}\right)^{2}
$$

However, in the evolution of the empirical approach from equation (1) to equation (2), based on separate tests carried out to determine the criterion for particle incipient motion, MPM determined an alternative correction of the form:

$$
\left(\frac{S}{S_{r}}\right)^{2 / 3}=\left(\frac{K_{b}}{K_{r}}\right)^{4 / 3}
$$

Hence one is left with the ambiguous conclusion that the bedform correction of MPM is expressed in terms of the ratio $K_{b} / K_{r}$, raised to a power of either $4 / 3$ or 2 . Meyer-Peter and Müller (1948) resolved this ambiguity with recourse to the data, finding that an exponent of $3 / 2$, i.e. a value in between $4 / 3$ and 2 , gave the best fit of the experimental data as per equation (2). This choice of exponent has the added advantage of allowing a Froude 
similarity collapse that was successfully used to derive a universal bedload transport law based on runs that included uniform material and size mixtures, different values of specific gravity of the sediment, and cases both with and without the presence of bedforms.

It is not the purpose of this paper to question the validity of this procedure for bedform correction, but to show that such a correction is not required when bedforms are absent. More specifically, it is shown that the use of what is in hindsight an inappropriate parameterization for flow resistance in these cases, led Meyer-Peter and Müller to the erroneous inclusion of an additional correction (reduction) of the effective bed shear stress in the form of $\left(K_{b} / K_{r}\right)^{3 / 2}$ for the plane-bed transport conditions. The parameterization for flow resistance used here became available only well after the work of MPM was published (Meyer-Peter and Müller 1948).

Meyer-Peter and Müller (1948) stated that the "evaluation of the measurements of the Laboratory confirms for all tests the fully developed turbulence, so that the coefficient of particle roughness may be calculated with sufficient accuracy from"

$$
K_{r}=\frac{26}{D_{90}^{1 / 6}}
$$

Equation (14) is based on the results of the famous set of experiments on pipe flow by Nikuradse (NACA 1950, which is an English translation of a document dating from 1933), who found that the bed roughness height, $k_{s}$, can be estimated as follows:

$$
k_{s}=D_{90}
$$

Van Rijn (1984) and Millar (1999), for example, have used results from several tests carried out for a range of grain sizes including both gravel and sand particles to demonstrate that this one-to-one scaling is misleading. Chien and Wan (1999) reinforce this claim by arguing that the procedure by which Nikuradse glued uniform sand particles to the pipe walls resulted in an effective roughness smaller than the actual size of the sand particles. An alternative, better tested parameterization is given by Kamphuis (1974), who concluded that for large values of the ratio of $H$ to $D_{90}\left(H / D_{90} \geq 10\right.$; see Kironoto and Graf 1994) and fully developed turbulent flow $\left(u_{b}^{*} k_{s} / v \geq 70\right.$; see Schlichting 1979), a better approximation for $k_{s}$ is:

$$
k_{s}=2 D_{90}
$$

124 out of the 135 runs comprising data sets ETH-up and ETH-nup complied with the criterion of $H / D_{90} \geq 10$, and all 135 tests corresponded to completely rough turbulent flow. As a result, the evaluation of the bed roughness 
height in the form of equation (16) is used from here onwards, unless explicitly stated in a different form. It should be noted here that the justification for amending equation (15) to equation (16) was not yet available to Meyer-Peter and Müller when they developed their relations of 1934 and 1948.

It is of interest to note as well that Jäggi (1984) reached a conclusion that is nearly equivalent to that of Kamphuis (1974). In particular, he modified the constant in equation (14) from 26 to a value between 20 and 22. If the form of equation (14) is retained but the transformation $D_{90} \rightarrow k_{s}$ is made, equation (14) now takes the form:

$$
K_{r}=\frac{26}{k_{s}^{1 / 6}}
$$

Introducing equation (16) into equation (17) yields:

$$
K_{r}=\frac{23.2}{D_{90}^{1 / 6}}
$$

i.e. a form very close to that obtained by Jäggi (1984).

It is well known the vertical profile of flow velocity for turbulent open-channel flow may be represented by a logarithmic law, leading to the Keulegan relation (Keulegan 1938) for depth-averaged flow velocity, $u$, in the hydraulically rough regime. Making the transformations $H \rightarrow r_{b}$ and $u^{*} \rightarrow u_{b}{ }_{b}$ (where $u^{*}=$ shear velocity), in order to incorporate the sidewall correction of Vanoni and Brooks presented in the previous section, the Keulegan relation can be expressed as:

$$
C_{Z}=\frac{1}{\kappa} \ln \left(11 \frac{r_{b}}{k_{s}}\right)
$$

where $C_{Z}=$ dimensionless Chezy resistance coefficient, is defined in the following way:

$$
C_{Z}=\frac{u}{u^{*}{ }_{b}}
$$

and $\kappa=0.4$ denotes the Karman constant. It should be noted that in analogy to the Manning-Strickler coefficient of roughness, a larger value of $C_{Z}$ implies a smaller resistance to the flow. It is also important to note that the original flow resistance relation proposed by Keulegan (1938) was based on the definition of $k_{s}$ given in equation (15), whereas here it is based on the improved definition of $k_{s}$ given in equation (16).

The relation (14) used by MPM to evaluate flow resistance can be reduced to the following form with the aid of equation (16) for the bed roughness height, and of equation (19b) for the definition of $C_{Z}$ : 


$$
C_{Z}=9.32\left(\frac{r_{b}}{k_{s}}\right)^{1 / 6}
$$

It has long been known that the Manning-Strickler power form of bed resistance given in equation (20) yields results that are very similar to those of the Keulegan form in equation (19a). One must ask, however, if (20) really does provide an accurate evaluation of bed resistance in the absence of bedforms. In order to test this, Figure 5 presents a comparison of the estimates provided by equation (20) against the measured values of the data set ETH-up for which bedforms were absent, as well as the data set ETH-nup for which bedforms were present in some cases. It is seen in this figure that nearly all the data for $C_{Z}$ plot below (20), implying that the boundary resistance is higher than predicted by this equation (20). In other words, with sidewall effects removed through $H \rightarrow r_{b}$ and $u^{*} \rightarrow u^{*}$, an observed value of $C_{Z}$ that is smaller than the one estimated via the equation (20) would mean that a component of flow resistance due to bedforms should be present in addition to the one associated with skin friction alone. Figure 5 thus indicates a measurable effect of bedforms not only in the results of data set ETH-nup for which bedforms may have been present, but also for data set ETH-up for which bedforms were verifiably absent! The implication is a contradiction; that is, correcting the boundary shear stress in equation (2) to extract only that portion obeying equation (20) results in a measurable correction for bedforms that are not actually present.

MPM argue somewhat unconvincingly that even in the absence of bedforms, the resistance offered by a mobile plane bed may be larger than that of a static plane bed, so accounting for the discrepancy in Figure 5. While this might in fact be true under certain regimes of bedload transport, it is not true in the case of the data sets without bedforms used by MPM to derive their relation. The fact that equation (20) does indeed underpredict plane-bed resistance (i.e. overpredict $C_{Z}$ ) can be demonstrated with reference to the fit of Manning-Strickler type to the Keulegan relation developed by Parker (1991):

$$
C_{Z}=8.10\left(\frac{r_{b}}{k_{s}}\right)^{1 / 6}
$$

where $k_{s}$ is given by (16) of Kamphuis (1974) rather than by (15) of Nikuradse (NACA 1950). A comparison of the estimates obtained with the power-law (21) versus: (i) the data set ETH-up for which bedforms were absent, (ii) the data set ETH-nup for which bedforms were present in some runs, and (iii) the data set GIL-up for which bedforms were absent, is given in Figure 6. Also included in this figure is the logarithmic law (19a) of Keulegan in which $k_{s}$ is evaluated from (16). It is seen that (21) provides an excellent fit of the data from the cases for which bedforms were 
not observed, while the experimental values of $C_{Z}$ remain, as expected, smaller than those predicted by the powerlaw (21) for the cases in which bedforms may have been present. The direct inference from this is that a resistance relation based on skin friction only, i.e. equation (21), is adequate and sufficient to explain the data for which bedforms were absent. That is, no bedform correction is needed to characterize the results of sets ETH-up and GIL-up. Given that $K_{b} \leq K_{r}$ in the original formulation of MPM, dropping the bedform correction means the whole curve presented in Figure 2 is shifted to the right. As a result, the parameters used to fit an equation to the data of Figure 2 must necessarily differ from those of equation (2), i.e. the form due to MPM. The resulting re-analysis is presented in the next section.

Summarizing, the use by MPM of a parameterization of skin friction that does not properly account for flow resistance, i.e. equation (14) or equation (15), was the source of their need to include a bedform-correction for cases in which bedforms were verifiably absent. In this regard, Figure 6 shows that by using an appropriate flow resistance relation, i.e. equation (21) with the aid of equation (16), it is found that for the sets ETH-up and GIL-up: (a) bedforms were not observed, and (b) there is no discernible difference on the bed resistance of a mobile bed versus a static bed.

\section{Re-analysis of the data and amended MPM bedload transport relation}

Data sets ETH-up and GIL-up for which bedforms were absent are now re-analysed in the form of equation (2), but with: (i) the Vanoni-Brooks sidewall correction, and (ii) no correction for bedforms. All the experimental information used subsequently corresponds to lower-regime plane-bed equilibrium transport conditions, and uniform material in the gravel-size range only.

Figure 7 presents the results of implementing the sidewall correction as per Vanoni and Brooks (Vanoni 1975). It can be easily seen that no correction may be necessary for channel aspect ratios, $B / H$, larger than 5.0. In many if not most experiments carried out in flume facilities, however, smaller values of $B / H$ prevail. In such cases, omitting the sidewall correction might result in a significant overprediction of the bedload transport rate. Based on the data from MPM for instance, it is seen in Figure 8 that most of the tests correspond to a dimensionless excess shear stress (after applying the Vanoni-Brooks sidewall correction) ranging between 0.02 and 0.10 . If no sidewall correction is applied for this range of shear stress, the estimate of the bedload transport rate would be larger by a factor of 1.27 to 1.66 for the $65 \%$ of the experiments in which the effect of wall drag is at least $10 \%$ of the boundary shear stress 
(according to Figure 7). Moreover, an overprediction factor of 1.45 to 2.10 would be obtained for the $39 \%$ of the experiments in which sidewall effects account for at least $15 \%$ of the boundary shear stress (according to Figure 7). Hence, a proper channel-averaged evaluation of bedload transport under controlled laboratory conditions should consider, as a minimum requirement, splitting the estimate of the boundary shear stress into bed and wall components, with only the first one used in the analysis of bedload transport.

Working with values of the boundary shear stress acting on the bed region, $\tau_{b}$, that have been corrected for sidewall effects with the Vanoni-Brooks method but not corrected for nonexistent form drag, two new power laws of the form of equation (2) have been developed. The first is presented as equation (22) below

$$
q^{*}=4.93\left(\tau_{b}^{*}-0.0470\right)^{1.60}
$$

where

$$
\tau_{b}^{*}=\frac{\tau_{b}}{\rho \operatorname{Rg} D_{m}}
$$

It keeps the same value of 0.0470 used by MPM for the critical Shields number, while a new value of 1.60 for the exponent is obtained from a statistical fitting of the experimental results. The second is presented as equation (24) below

$$
q^{*}=3.97\left(\tau_{b}^{*}-0.0495\right)^{1.50}
$$

It keeps the same exponent of 1.50 used by MPM, whereas the "effective" critical Shields number of 0.0495 is obtained from a statistical fitting of the data. In either case, the final outcome of the re-analysis is a line of best fit that gives estimates of the bedload transport rate that are smaller than the ones predicted with equation (2) by a factor of 2.0 to 2.5. This is shown in Figure 8, where the famous relation of MPM appears as an upper envelope of a data set that is much better fit by either of the alternatives (22) or (24).

It is again emphasized here that the goal of the present paper is not to propose a new or improved universal predictor of the bedload transport rate. Rather, the goal is to a) highlight the fact that the form drag correction of MPM is unnecessary in the context of the plane-bed transport data used to derive the MPM bedload transport relation, and b) modify the MPM bedload transport relation into a simpler form that uses no form drag correction for plane-bed conditions.

Hunziker and Jäggi (2002) have previously indicated that bedload transport rates are overpredicted when the MPM relation is applied to sediment mixtures. They attributed this to the fact that the condition of equal mobility for 
all grain sizes does not always hold, and as a result mobile-bed armor can develop in gravel-bed streams. A similar remark about the lack of accuracy of the MPM relation was given by Smart and Jäggi (1983) and Smart (1984), both in reference to the prediction of bedload transport rates for bed slopes steeper than 0.02 .

In the specific case of uniform bed sediment, Hunziker (1995) stated that the procedure used by MPM to correct for bedforms resulted in a form drag that is too large. The reason for this is the inaccurate parameterization of skin friction used by MPM, i.e. equation (14). This result is consistent with the earlier results of Jäggi (1984), Smart and Jäggi (1983), and also with the re-analysis presented here in the context of equation (20). So Hunziker (1995) decided to use the alternative bedform correction proposed by Yalin and Scheuerlein (1988). This correction was intended to account not only for bedform effects, but to consider also the influence of particles moving in bedload transport. The boundary shear stress is thus "bedform-corrected" even for cases in which bedforms are absent. Hunziker (1995) then proceeded to perform a new regression analysis of data from ETH for experiments on bedload transport of uniform gravel. This set included: (i) only the part of the data from ETH used by Meyer-Peter and Müller (1948) to develop their original relation (i.e. ETH-up, but not GIL-up), and (ii) the data from Smart and Jäggi (1983). As a result, Hunziker (1995) derived the following improved MPM-relation, i.e. equation (12) quoted in Hunziker and Jäggi (2002):

$$
q^{*}=5\left(\tau_{H-Y S}^{*}-0.05\right)^{1.50}
$$

where $\tau_{H-Y S}^{*}=$ dimensionless boundary shear stress, after including the same sidewall correction procedure used by MPM (Meyer-Peter and Müller 1948) but now implementing the bedform correction of Yalin and Scheuerlein (1988) instead of the original bedform correction used by MPM. This modified form of the MPM relation, i.e. equation (23), predicts transport rates that are 0.42 to 0.57 times that of the original relation (2) when applied to the range of boundary shear stresses covering the data sets ETH-up and GIL-up re-analyzed here.

Equation (25) is similar to equations (22) and (24), and the main reason for the downward adjustment in transport rate offered by Hunziker (1995) is similar to that offered in the present work: MPM overcorrected for form drag. The valuable conclusion of Hunziker (1995) is, nevertheless, incomplete and clouded by extraneous factors. It is clouded by the implication that the re-evaluation of the MPM relation depends in some way on the data of Smart and Jäggi (1983), so the problem may not necessarily be with MPM's analysis itself. It is incomplete in the sense that it indicates that some form of correction for form drag, the one according to Yalin and Scheuerlein (1988), is still required even for data without bedforms. The essential points of the present work are as follows: (a) in 
contradistinction to MPM, Hunziker (1995) and Hunziker and Jäggi (2002), no form drag correction whatsoever is needed or should be used when analyzing the data without bedforms used by MPM; and (b) when the original data for plane beds used by MPM and only that data, i.e. without inclusion of other data sets such as Smart and Jäggi (1983), are re-analyzed without the unnecessary form drag correction, the result is a regression relation that predicts not more than half of the load that would be predicted by the original MPM bedload equation (2) in the absence of the MPM form drag correction.

When applied to data sets ETH-up and GIL-up that correspond to lower-regime plane-bed transport of uniform bed material, the error norm of the bedload transport rates predicted with any of the two amended forms of the MPM relation presented in this paper is smaller than the one obtained with the modified relation of Hunziker (1995). The improvement on the prediction is particularly important for dimensionless transport rates ranging between $10^{-3}$ and $10^{-1}$. In this range, the error norm associated to equation (22) for instance, is one-third smaller than that related to equation (25).

\section{Conclusions}

The bedload equation of Meyer-Peter and Müller (1948) includes a form drag correction that is intended to account for flow resistance of the stream bed due to factors other than skin friction (e.g., bedforms or moving bedload particles). MPM introduced this correction after finding that a flow resistance relation for skin friction, based on Strickler (1923) and Nikuradse (NACA 1950), underpredicted the overall bed resistance measured in their flume experiments. It is demonstrated here with recourse to only the data pertaining to plane-bed equilibrium transport of uniform sediment used by MPM, however, that this form drag correction is unnecessary for plane-bed conditions and should be dropped. Since the form of the MPM bedload transport equation itself that resulted from their data analysis is critically dependent upon this unnecessary form drag correction, a re-analysis of the data indicates a substantially revised form of MPM.

Put simply, this revision can be described as follows in the context of lower-regime plane-bed transport. The original MPM formulation makes no error in obtaining a curve fit for the bedload transport rate. Instead, their curve fitting is forced to correct one error (including nonexistent form drag) by adding another (increasing the coefficient in the bedload transport relation). So if the practitioner is to use the original MPM bedload relation (with a coefficient that is about twice as high as it should be), then the (unnecessary and incorrect) form drag correction of 
MPM must be used in order to obtain predictions that are faithful to the plane-bed data used by MPM. The practitioner will find it much easier to instead use one of the two modified MPM bedload relations proposed here (which for the most part involve a significantly lowered coefficient) in the absence of any form drag correction. The modified formulation is equally faithful to the original data, is simpler to use and has a firmer scientific basis.

Hunziker (1995) had previously realized the existence of a problem with the analysis done by MPM. He attempted to "fix" (i.e. improve the validity of) the MPM-equation by: (i) adding a new set of data to the regression analysis (the one due to Smart and Jäggi 1983), and (ii) muting, but not eliminating the MPM correction for form drag. The re-analysis presented in this paper is different, in the sense that it does not attempt to "fix" the MPMequation, but instead results in its re-derivation. By using the same data used by MPM for runs without bedforms, and only that data, it is shown here that no correction for form drag is needed for these runs. More specifically, it is shown that the resistance relation satisfied for the mobile-bed experiments without bedforms used by MPM is identical to that observed for a static bed composed of the same material.

In 1948 Meyer-Peter and Müller would not have had access to the revised resistance relations that demonstrate that no form drag correction was needed in their analysis of data on plane-bed transport. Here their data have been re-analysed in precisely the way that Meyer-Peter and Müller would have done it had they had access to the relevant information.

\section{Acknowledgements}

This work was supported by the National Science Foundation via Agreement Number EAR-0207274. Additional support was derived from the STC program of the National Science Foundation via the National Center for Earthsurface Dynamics under Agreement Number EAR-0120914. This paper represents a contribution of the research of the National Center for Earth-surface Dynamics in the area of channel dynamics. Special thanks go to Prof. Willi H. Hager from ETH, and to Prof. John Buffington from University of Idaho, for providing copies of the original experimental data and related papers produced by the research group of ETH. A preliminary version of the present review of the MPM bedload transport relation may be found in Wong (2003). We also acknowledge E. Meyer-Peter, R. Müller and other researchers of ETH Zürich of the same era, whose high standards for data collection, archiving and analysis serve as a model for subsequent research on sediment transport. 


\section{Notation}

The following symbols are used in this paper:

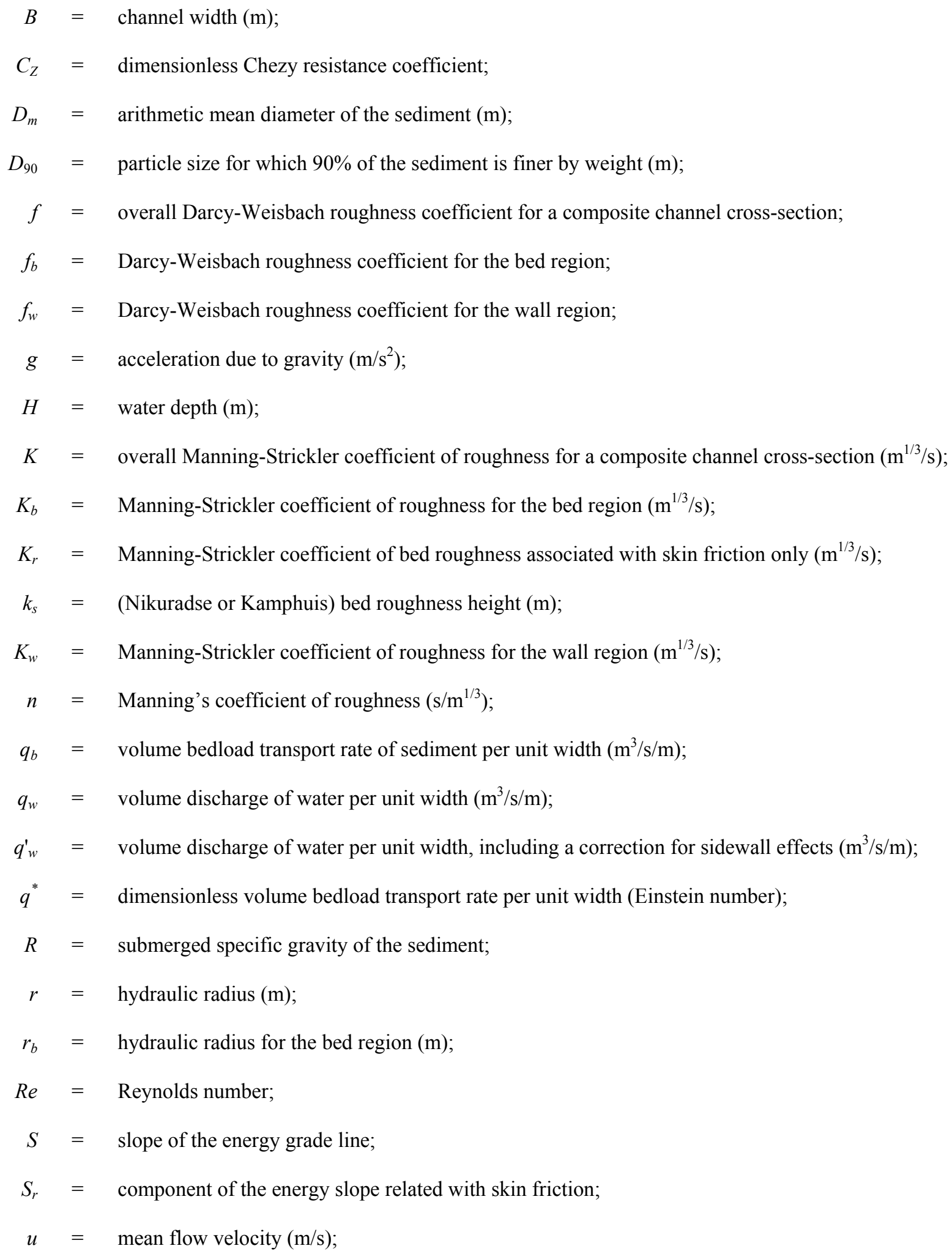




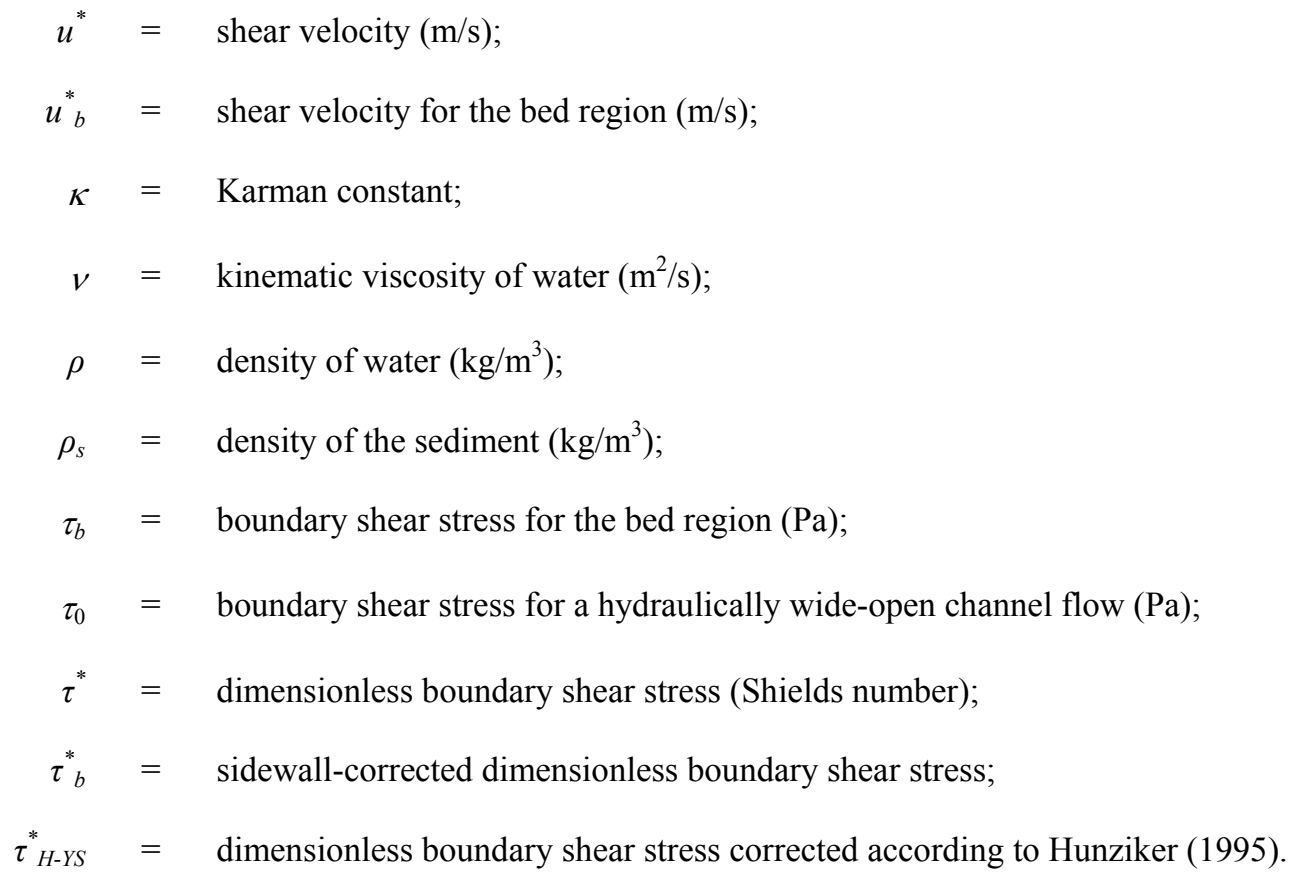

\section{References}

Abdel-Fattah, S., Amin, A., and Van Rijn, L. C. (2004). "Sand transport in Nile River, Egypt." J. Hydraul. Eng., ASCE, 130(6), 488-500.

Ashworth, P. J., Bennett, S. J., Best, J. L., and McLelland S. J., eds. (1996). Coherent flow structures in open channels, John Wiley \& Sons Ltd., Chichester, United Kingdom, 733 pp.

Barry, J. J., Buffington, J. M., and King, J. G. (2004). “A general power equation for predicting bed load transport rates in gravel bed rivers." Water Resour. Res., AGU, 40, W10401, doi:10.1029/2004WR003190.

Bettess, R., and Frangipane, A. (2003). "A one-layer model to predict the time development of static armour." J. Hydraul. Res., IAHR, 41(2), 179-194.

Bogárdi, J. (1974). Sediment transport in alluvial streams, Akadémiai Kiadó, Budapest, Hungary, 826 pp.

Bolla Pittaluga, M., Repetto, R., and Tubino, M. (2003). "Channel bifurcation in braided rivers: Equilibrium configurations and stability.” Water Resour. Res., AGU, 39(3), 1046, doi:10.1029/2001WR001112

Bravo-Espinosa, M., Osterkamp, W. R., and Lopes, V. L. (2003). "Bedload transport in alluvial channels." J. Hydraul. Eng., ASCE, 129(10), 783-795.

Cao, Z., and Carling, P. (2002). "Mathematical modeling of alluvial rivers: reality and myth. Part I: General review." Proc. Institution Civil Engineers, Water \& Marit. Eng., 154(3), 207-219. 
Chang, H. H. (1992). Fluvial processes in river engineering, Krieger Publishing Company, Malabar, Florida, $432 \mathrm{pp}$.

Chien, N. (1954). "Meyer-Peter formula for bed-load transport and Einstein bed-load function." M.R.D. Sediment Series No. 7, University of California-Berkeley, and The Missouri River Division, U.S. Army Corps of Engineers, Berkeley, California, 32 pp.

Chien, N., and Wan, Z. (1999). Mechanics of sediment transport, ASCE, Reston, Virginia, 913 pp.

Defina, A. (2003). "Numerical experiments on bar growth.” Water Resour. Res., AGU, 39(4), 1092, doi:10.1029/ 2002WR001455.

Ettema, R., and Mutel, C. F. (2004). "Hans Albert Einstein: Innovation and compromise in formulating sediment transport by rivers." J. Hydraul. Eng., ASCE, 130(6), 477-487.

Garde, R. J., and Ranga Raju, K. G. (1985). Mechanics of sediment transportation and alluvial stream problems, $2^{\text {nd }}$ ed., Wiley Eastern Limited, New Delhi, India, 618 pp.

Gaudio, R., and Marion, A. (2003). "Time evolution of scouring downstream of bed sills." J. Hydraul. Res., IAHR, 41(3), 271-284.

Gilbert, G. K. (1914). "The transportation of debris by running water." USGS Professional Paper No. 86, U.S. Geological Survey, Washington, D.C., 263 pp.

Graf, W. H. (1971). Hydraulics of sediment transport, McGraw-Hill, Inc., New York, 513 pp.

Hey, R. D. (1979). "Flow resistance in gravel-bed rivers.” J. Hydraul. Div., ASCE, 105(HY4), 365-379.

Hunziker, R. P. (1995). "Fraktionsweiser Geschiebetransport." Mitteilungen der Versuchsanstalt für Wasserbau, Hydrologie und Glaziologie, 138, Eidgenössische Technische Hochschule (ETH), Zürich, Switzerland, 209 pp. (in German).

Hunziker, R. P., and Jäggi, M. N. R. (2002). "Grain sorting processes.” J. Hydraul. Eng., ASCE, 128(12), 1060-1068.

Jäggi, M. (1984). “Abflußberechnung in kiesführenden Flüssen.” Wasserwirtschaft, Friedrich Vieweg, Wiesbaden, Germany, 74(5), 263-267 (in German).

Kamphuis, J. W. (1974). “Determination of sand roughness for fixed beds.” J. Hydraul. Res., IAHR, 12(2), 193-203.

Keulegan, G. H. (1938). "Laws of turbulent flows in open channels.” J. Res. US National Bureau Standards, 21, 707-741. 
Kironoto, B. A., and Graf, W. H. (1994). "Turbulence characteristics in rough uniform open-channel flow.” Proc. Institution Civil Engineers, Water \& Marit. Eng., 106, 333-344.

Knappen, M. A. F., and Hulscher, S. J. M. H. (2003). "Use of a genetic algorithm to improve predictions of alternate bar dynamics.” Water Resour. Res., AGU, 39(9), 1231, doi:10.1029/2002WR001793.

Manning, R. (1891). "On the flow of water in open channels and pipes." Trans. Institution Civil Engineers of Ireland, 20, 161-207.

Martin, Y. (2003). "Evaluation of bed load transport formulae using field evidence from the Vedder River, British Columbia." Geomorphology, 53(1-2), 75-95.

Meyer-Peter, E., Favre, H., and Einstein, H. A. (1934). "Neuere Versuchsresultate über den Geschiebetrieb." Schweizerische Bauzeitung, 103(13), Zürich, Switzerland, 147-150 (in German).

Meyer-Peter, E., and Müller, R. (1948). "Formulas for bed-load transport.” Proc., 2nd Meeting, IAHR, Stockholm, Sweden, 39-64.

Mikoš, M., Pender, G., Hoey, T., Shvidchenko, A., and Petkovšek, G. (2003). "Numerical simulation of graded sediment transport.” Proc. Institution Civil Engineers, Water \& Marit. Eng., 156(1), 47-51.

Millar, R. G. (1999). “Grain and form resistance in gravel-bed rivers.” J. Hydraul. Res., IAHR, 37(3), 303-312.

NACA (1950). "Laws of flow in rough pipes." Translation of "Strömungsgesetze in rauhen Rohren" by J. Nikuradse (1933), Technical Memorandum No. 1292, National Advisory Committee for Aeronautics, Washington, D.C., $62 \mathrm{pp}$.

Nielsen, P., and Callaghan, D. P. (2003). "Shear stress and sediment transport calculations for sheet flow under waves." Coast. Eng., Elsevier, 47(3), 347-354.

Ota, J. J., and Nalluri, C. (2003). "Urban storm sewer design: Approach in consideration of sediments." J. Hydraul. Eng., ASCE, 129(4), 291-297.

Parker, G. (1991). “Selective sorting and abrasion of river gravel. II: Applications.” J. Hydraul. Eng., ASCE, 117(2), 150-171.

Raudkivi, A. J. (1976). Loose boundary hydraulics, $2^{\text {nd }}$ ed., Pergamon Press Ltd., Oxford, United Kingdom, 397 pp.

Rouse, H. (1946). Elementary mechanics of fluids, John Wiley and Sons, New York, 376 pp.

Schlichting, H. (1979). Boundary-layer theory, McGraw-Hill Book Company, 7th ed., New York, 817 pp. 
Simons, D. B., and Şentürk, F. (1977). Sediment transport technology, Water Resources Publications, Fort Collins, Colorado, $807 \mathrm{pp}$.

Singh, A. K., Kothyari, U. C., and Ranga Raju, K. G. (2004). "Rapidly varying transient flows in alluvial rivers." J. Hydraul. Res., IAHR, 42(5), 473-486.

Smart, G. M. and Jäggi, M. N. R. (1983). “Sediment transport on steep slopes.” Mitteilungen der Versuchsanstalt für Wasserbau, Hydrologie und Glaziologie, 64, Eidgenössische Technische Hochschule (ETH), Zürich, Switzerland, $191 \mathrm{pp}$.

Smart, G. M. (1984). “Sediment transport formula for steep channels.” J. Hydraul. Eng., ASCE, 110(3), 267-276.

Strickler, A. (1923). "Beiträge zur Frage der Geschwindigkeitsformel und der Rauhigkeitszahlen für Ströme, Kanäle und geschlossene Leitungen.” Mitteilungen des Amtes für Wasserwirtschaft, 16, Eidgenössisches Departement des Innern, Bern, Switzerland (in German).

Vanoni, V. A., ed. (1975). "Sedimentation Engineering." ASCE Manuals and Reports on Engineering Practice No. 54, ASCE, New York, 745 pp.

Van Rijn, L. C. (1984). "Sediment transport, Part I: Bed load transport.” J. Hydraul. Eng., ASCE, 110(10), $1431-1456$.

Wilcock, P. R. (2004). "Sediment transport in the restoration of gravel-bed rivers." Proc. (CD-Rom), EWRI Congress 2004, ASCE, Salt Lake City, Utah, 11 pp.

Wong, M. (2003). “Does the bedload transport relation of Meyer-Peter and Müller fits its own data?" Proc. (CDRom), 30th IAHR-Congress, IAHR, Thessaloniki, Greece, 8 pp.

Yalin, M. S., and Scheuerlein, H. (1988). "Friction factors in alluvial rivers." Institut für Wasserbau und Wassermengenwirtschaft und Versuchsanstalt für Wasserbau Oskar v. Miller in Obernach, 59, Technische Universität München, Munich, Germany, 76 pp.

Yang, C. T. (1971). Sediment transport: Theory and practice, The McGraw-Hill Companies, Inc., New York, $396 \mathrm{pp}$.

Yang, S. C. (2005). "Prediction of total bed material discharge.” J. Hydraul. Res., IAHR, 43(1), 12-22.

Yen, B. C. (2002). “Open channel flow resistance.” J. Hydraul. Eng., ASCE, 128(1), 20-39. 


\section{Figure captions}

Figure 1 Reproduction of the data sets ETH-up and GIL-up in the form of equation (1), for uniform material and lower-regime plane-bed equilibrium transport conditions.

Figure 2 Reproduction of the data sets ETH-up and ETH-nup in the form of equation (2), for normal flow conditions, with and without bedforms, and including the sidewall and bedform corrections of MPM.

Figure 3 Plots of the Manning-Strickler coefficient of roughness for the wall region, $K_{w}$, as a function of: (a) water discharge per unit channel width, $q_{w}$, and (b) channel aspect ratio, $B / H$. Data used for plot include results from ETH-up and ETH-nup. No correlation is apparent in either case.

Figure 4 Variation of the Darcy-Weisbach roughness coefficient for the wall region, $f_{w}$, as a function of: (a) water discharge per unit channel width, $q_{w}$, and (b) channel aspect ratio, $B / H$. Data used for plot include results from ETH-up and ETH-nup.

Figure 5 Comparison of flow resistance measurements for the data sets ETH-up and ETH-nup against equation (20).

Figure 6 Comparison of flow resistance measurements for the data-sets ETH-up, GIL-up and ETH-nup against the logarithmic law (19a) of Keulegan and Parker’s form (21) of Manning-Strickler.

Figure 7 Results of the Vanoni-Brooks sidewall correction for the MPM and GIL data sets in which bedforms were not observed, as a function of channel aspect ratio, $\mathrm{B} / \mathrm{H}$.

Figure 8 Comparison of original empirical relation (2) proposed by MPM, and its amended version (22) recommended for the case of lower-regime plane-bed normal flow equilibrium transport conditions. 


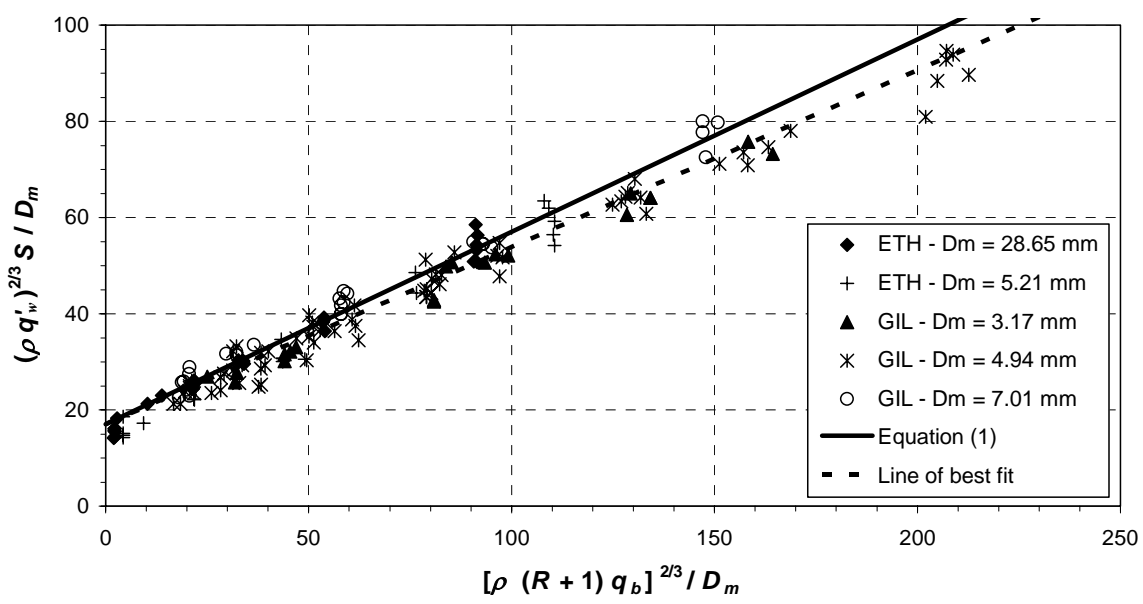

Figure 1 


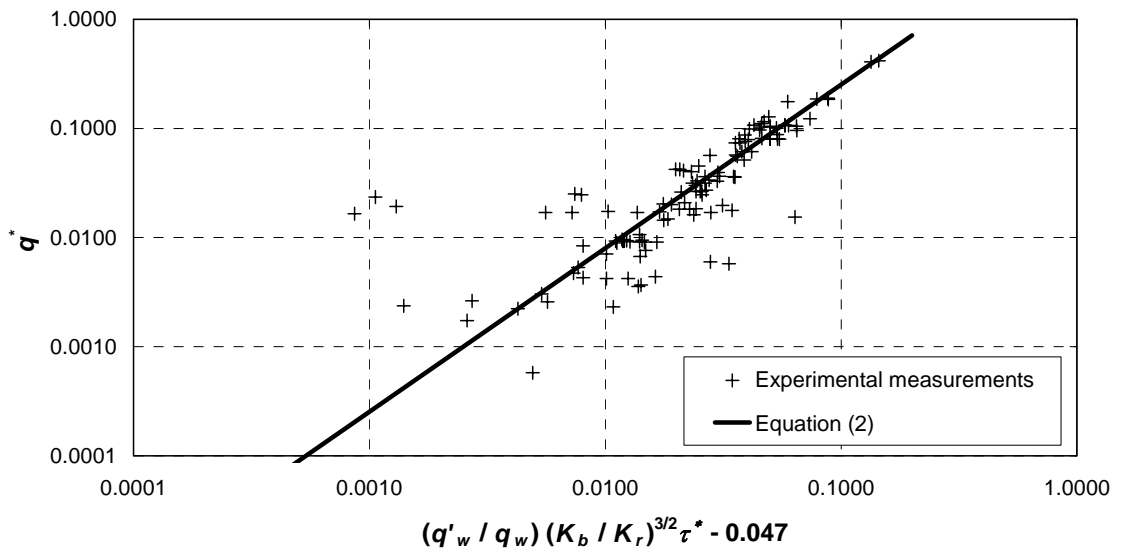

Figure 2 
(a)

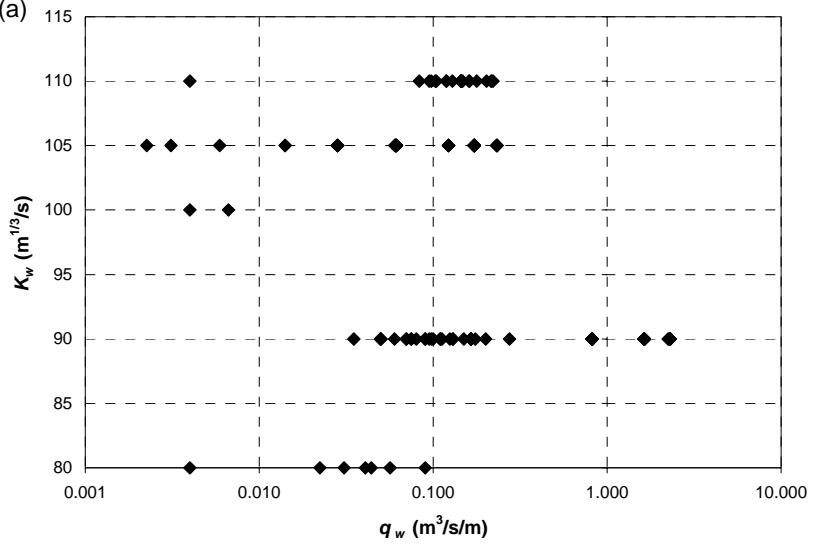

(b)

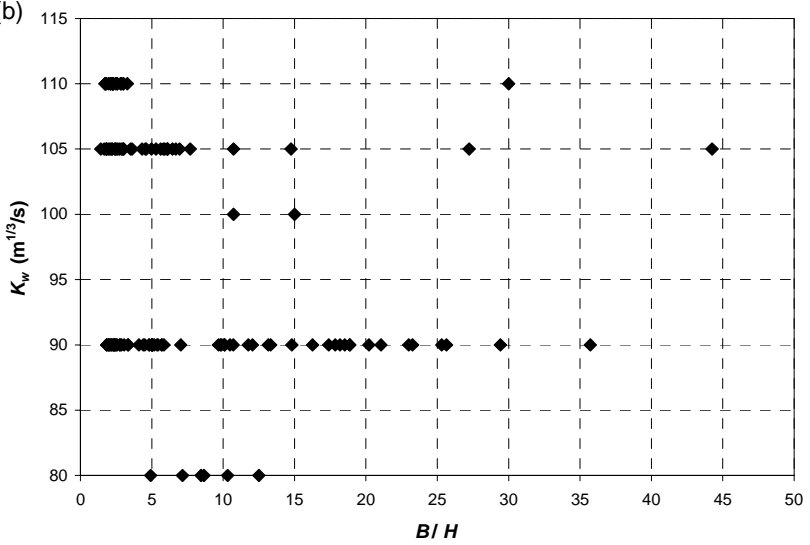

\section{Figure 3}



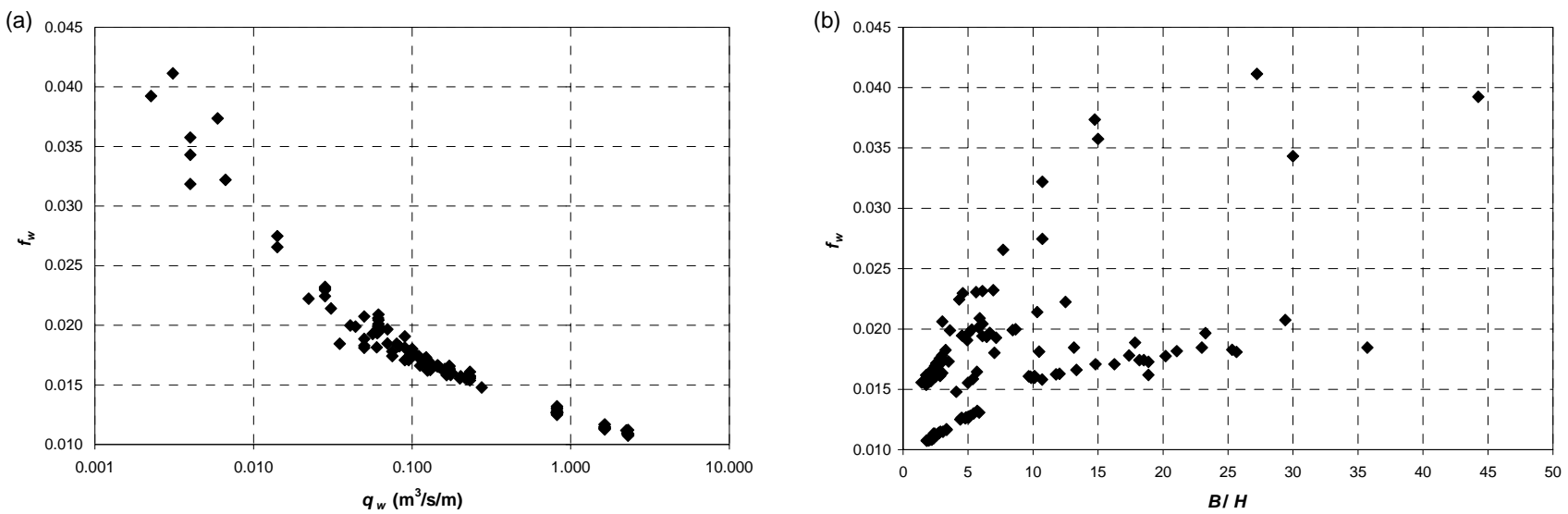

\section{Figure 4}




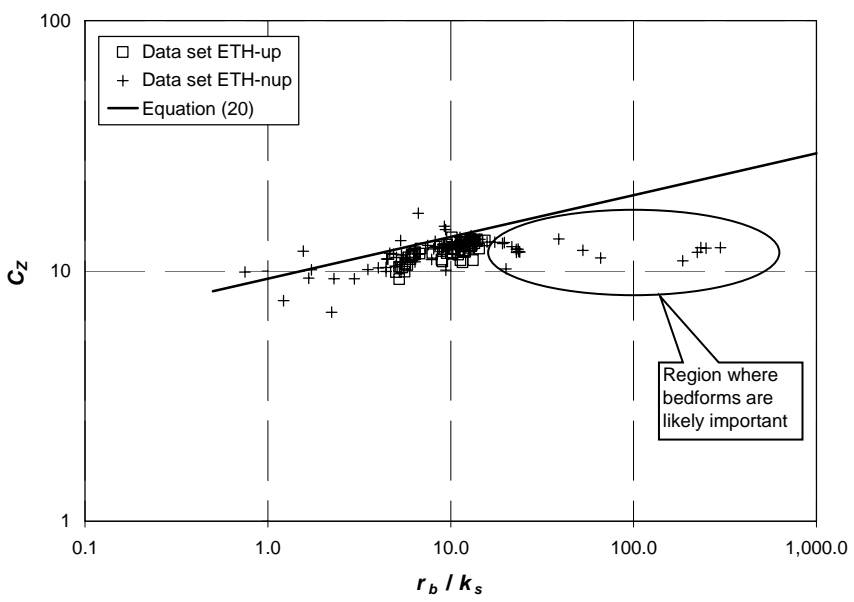

Figure 5 


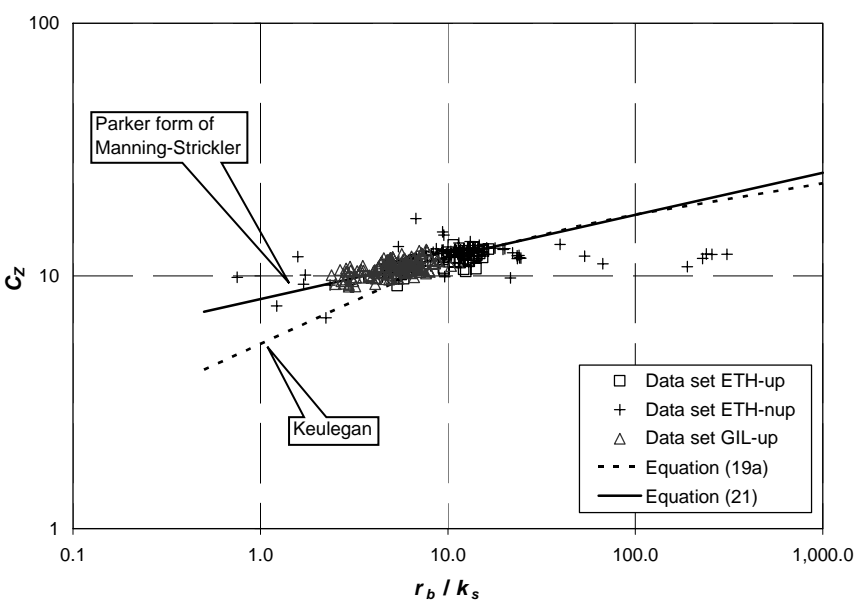

Figure 6 


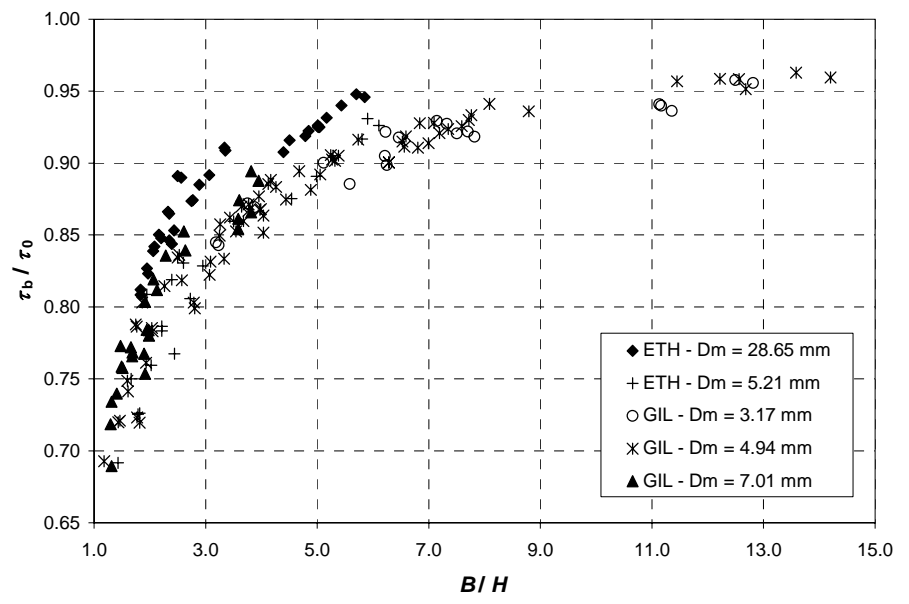

Figure 7 


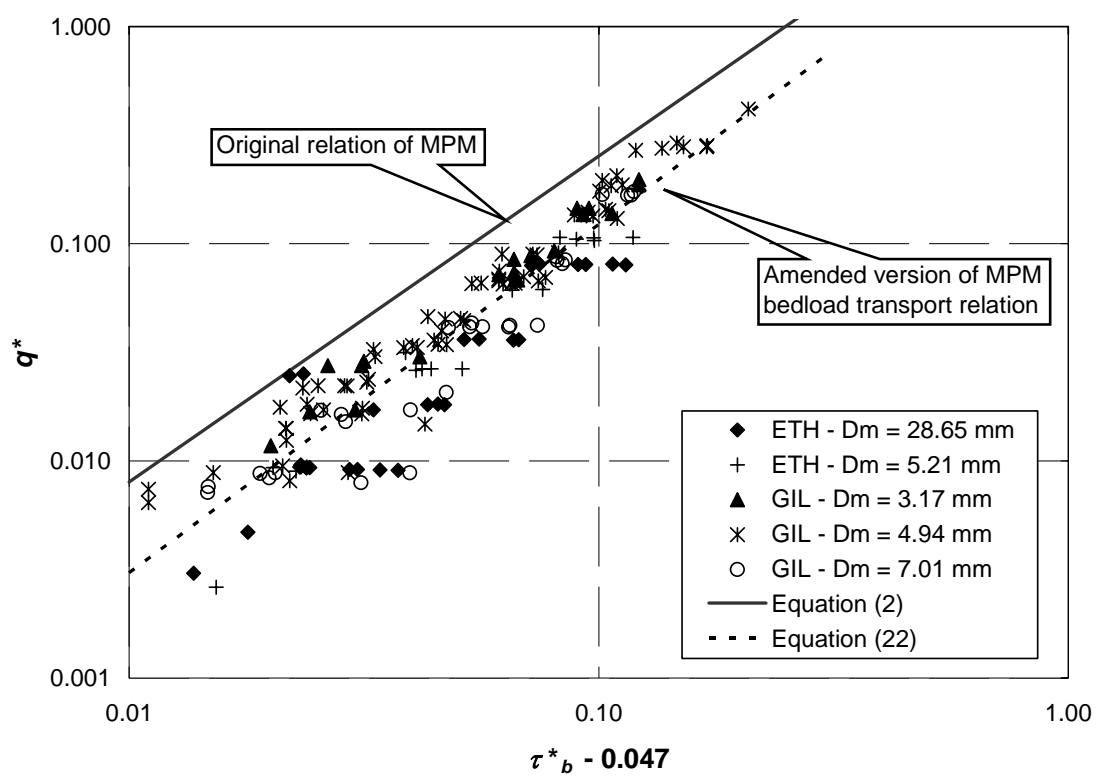

\section{Figure 8}

